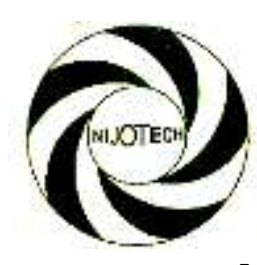

Nigerian Journal of Technology (NIJOTECH)

Vol. 38, No. 1, January 2019, pp. 153 - 164

Copyright@ Faculty of Engineering, University of Nigeria, Nsukka,

Print ISSN: 0331-8443, Electronic ISSN: 2467-8821 www.nijotech.com

http://dx.doi.org/10.4314/njt.v38i1.20

\title{
VIRTUAL SYNCHRONOUS GENERATOR: AN OVERVIEW
}

\author{
O. O. Mohammed ${ }^{1, *}$, A. O. Otuoze ${ }^{2}$, S. Salisu ${ }^{3}$, O. Ibrahim $^{4}$ and N. A. Rufa'i ${ }^{5}$ \\ 1, 2, 4, DePARTMENT OF EleCtRICAL \& EleCTRONICS ENGINEERING, UNIVERSITY OF ILORIN, ILORIN, KWARA STATE, NIGERIA. \\ 3, Department of Electrical Engineering, Ahmadu Bello University, Zaria, Kaduna State, Nigeria. \\ 5, DePARTMENT OF ELECTRICAL ENGINEERING, BAYERO UNIVERSITY, KANO. KANO STATE, NIGERIA \\ E-mail addresses: ${ }^{1}$ mohammed.oo@unilorin.edu.ng, ${ }^{2}$ otuoze.ao@unilorin.edu.ng, ${ }^{3}$ s.salisu@live.com, \\ ${ }^{4}$ reacholaibrahim@gmail.com, ${ }^{5}$ nabilarufai@yahoo.com
}

\begin{abstract}
The continuous increase in the penetration of renewable energy (RE) based distributed generations (DGs) in the power system network has created a great concern on the stability of the existing grid. Traditional bulk power plants, which are dominated by synchronous machines (SMs) can easily support system instability, due to the inherent rotor inertia and damping characteristic, as well as voltage (reactive power) control ability. Nevertheless, converter based $\mathrm{RE}$ has some special characteristics, such as stochastic real and reactive power output, quick active and reactive power response, small output impedance, and little or no inertia and damping property thereby causing frequency and voltage instability in the system. To solve this problem, virtual synchronous generator (VSG) concept was proposed to emulate some of the features of conventional SG through converter control strategy in order to provide additional inertia virtually. Different control schemes for VSG has been proposed in literature. Surprisingly, an overview of these schemes is yet to be efficiently presented. This paper presents an overview of the VSG control schemes. It provides the concepts, the features of the control schemes and the applications of VSG. Finally, the crucial issues regarding VSG control schemes and the necessary improvement that need to be addressed are highlighted.
\end{abstract}

Keywords: Distributed generation, Synchronous generator, Virtual synchronous generator, Power electronic converter, Energy storage system, Frequency control

\section{INTRODUCTION}

The level of distributed generation (DG) resources and renewable energy sources (RES) envisaged to be integrated into the conventional grid is tremendously being explored. The appetite to "Go Green" due to concerns on the dwindling non-renewable energy sources and the preservation of environment has forced various countries to devise means of accessing renewable energy for electric power generation. The European Union (EU) has given the regulations to realize a $20 \%$ objective from the entire share of energy from RE sources by 2020 [1] and this has resulted to an increase in the level of DG. DG has been the impetus in the transformation of the traditional vertical grid scheme to a much more looped and alloyed grid scheme as explained in [2], Fig. 1 [3] depicts the grid transformation.
The most commonly used renewable energies are the photovoltaic and wind power; they are environmentally friendly and abundant. RE has experienced fast technological growth, which contributes to their availability at considerably lowcost [4]. This has resulted in a drastic reduction in fossil fuel consumption of many countries, which subsequently maintain a reduced cost than normal prices and improve the living standard with a greener environment. Another advantage is their key participation in support of electrical network in remote and rural areas electrification [5]. The global investment in REs in current years as depicted in Fig. 2 shows that wind and solar energy sources have become more popular renewables in recent years [6].

\footnotetext{
* Corresponding author, tel: +234-803-463-8575
} 


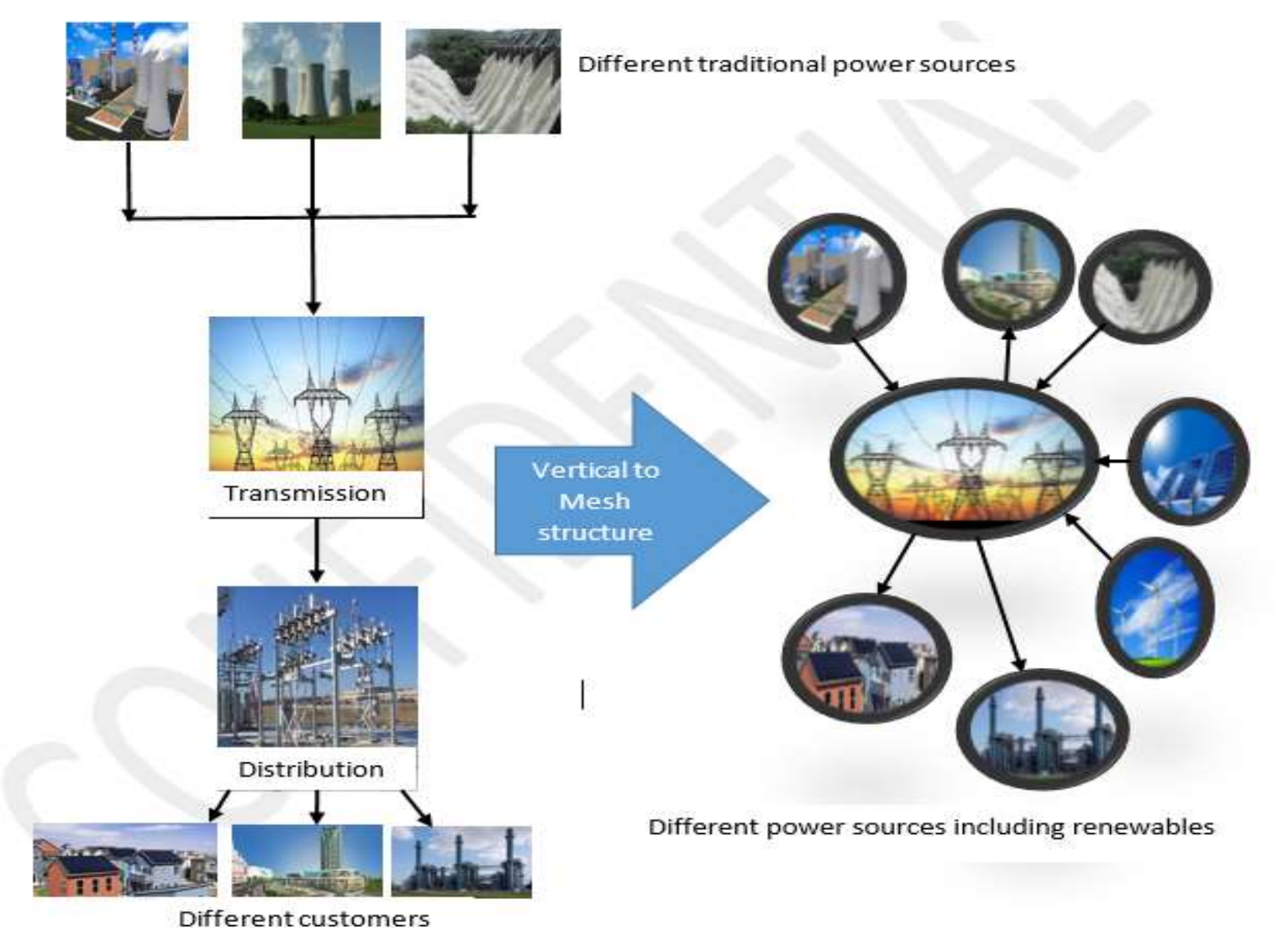

Figure 1: Power network structural transformation from vertical to mesh structure with DG

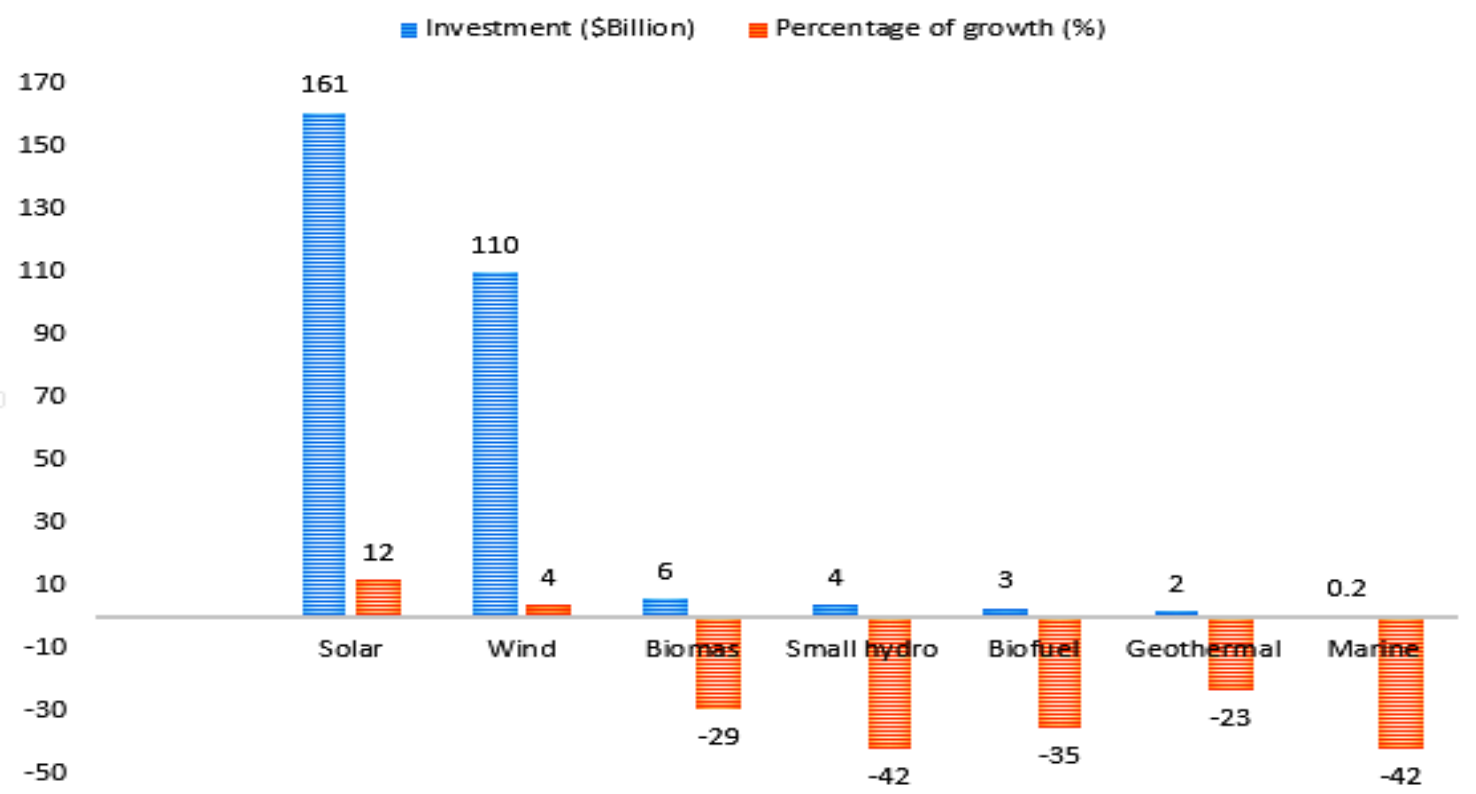

Fig. 2 Growth in renewable energy investment in the whole world from 2014 to 2015

However, in the near future, power electronic converters (PECs) based DGs are expected to have a remarkable influence on sizeable power systems as a substantial part of the conventional synchronous generators (SGs) in the systems will be substituted by PECs based generations [7]. Traditional bulk power plants, which are dominated by synchronous machines (SMs) with speed governor and excitation control, can automatically regulate speed governor to support frequency instability events, due to the 
inherent rotor inertia and damping characteristic, as well as voltage (reactive power) control $[8,9]$. Nevertheless, converter based RES have some special characteristics, such as stochastic output, real and reactive power supplied to AC networks, quick active and reactive power response, small output impedance, and little or no inertia and damping property $[10,11]$. These RE sources cause fluctuations in power generation, system frequency deviations, and voltage rise due to reverse power from PV generation [8]. Therefore, the increasing penetration level of DG will have enormous effects on the dynamic response and power system stability. The main concern of these DG technologies is maximization of power supply to the grid while delivering efficient and operability in case of system faults and disturbances [7, 12]. Normally, the safe operation of large centralised power stations is not threatened by the influence of a few small-size DG units thus their effects are negligible.

Nevertheless, with large number of higher capacities DG units, the entire dynamics of power systems are considerably affected [13]. This scenario has instigated remarkable research and development on the methods to control the grid-connected DG via power converters. Some researchers proffer solution to this problem through the evolution of droop-based control systems for microgrids operation dominated by PECs and converters in a stand-alone operation [14-17]. In such a technique, the energy storage is employed in the DG and the converters employ droop control mechanism to mimic the primary frequency and voltage regulation features of the synchronous generator (SG). As such, the converters with DG and Energy Storage Systems (ESS) can be viewed as voltage source integrated into the network to support system voltage and frequency. Converters with droop control can rapidly share load power in parallel operation, in that it has no inertia, it has poor frequency regulation.

In order to enhance the frequency stability of the DG systems, virtual synchronous generator (VSG) concept was proposed [2] to emulate the external features of the SG through converter control strategy [18], in order to provide additional inertia virtually $[19,20]$. VSG can be developed and implemented for DG systems by employing short-term ESS and PECS with efficient control technique which then operates like conventional SG by exhibiting some amount of inertia and damping characteristics for short period of time [8]. This eventually provides the necessary supports for power system stability in the presence of large integration of DG systems.

This paper presents an overview of VSG control mechanisms, it provides the concept, features and the review of the existing models as well as highlighting the necessary improvement that needed to be done for proper control of DGs. The remainder of this paper is structured as follows. Section 2 discusses the mechanism of synchronous generator Iinherent stability mechanism and section 3 presents the concept of VSG. The review of the existing VSG control mechanisms is highlighted in section 4, section 5 gives a brief detailed application of VSG and the related challenges are discussed in section 6 while section 7 concludes the study.

\section{SYNCHRONOUS GENERATORS' INHERENT STABILITY MECHANISM}

It is very important to discuss the essential inherent properties of a SG that are established to be very critical in the stability and reliability operation of a power system, namely: the inertia due to rotating masses, damping effect due to the damper windings in the rotor and the speed-droop characteristics for load sharing [21].

\subsection{Inertia Due to Rotating Masses}

As the SG rotates, the field and damper windings of the rotor generate a sinusoidal flux in the air-gap, which consequently creates an EMF in the armature terminals. Considering the general swing equation of the SG dynamics,

$$
J \frac{d \omega}{d t}=\tau_{m}-\tau_{e}-D . \Delta \omega
$$

In equation (1), $J$ is moment of inertia of rotating masses (turbine and generator rotor), $\omega$ is the angular speed of the rotor, $\omega_{s}$ is the synchronous speed, $\Delta \omega=\omega-\omega_{s}, \tau_{m}$ is the mechanical torque, $\tau_{e}$ is the electromagnetic torque and $D$ is the damping torque coefficient. Detail explanation about this can be found in [22].

\subsection{Damping Characteristic of the Damper Windings in the Rotor}

Damping (due to mechanical losses) of rotor is small and can be ignored for all practical purposes. Damping is mainly provided by damper or armature windings in SG. Due to small disturbances, the generator rotor undergoes speed deviations, the damper winding plays a crucial role in the restoration of the rotor synchronism, and it presents the 
damping effects in the SG $[3,22]$. Upon a fault, the response of the generator is analysed by breaking the total period of the fault into three stages termed as sub-transient, transient and steady state. The damping effect will only surface during the transient stage. Whenever the rotor speed is different from the synchronous speed, the air-gap flux, which is rotating at the synchronous speed will penetrate the damper windings thereby inducing an emf and current in them. The damping torque is therefore produced by the induced current and subsequently restores the synchronous speed of the rotor. During subtransient state, the damper windings have a screening effect opposing the changes in armature flux to penetrate them [22], while the steady-state stage is a stable state. It can be deduced from equation (1) that the swing equation in terms of power can be expressed as;

$$
J \omega \frac{d \omega}{d t}=P_{m}-P_{e}-P_{D}
$$

where $P_{D}=D . \Delta \omega=$ Damping power

Upon any disturbance of the rotor from the steady state point, the rotor either accelerate or decelerate depending on the nature of the disturbance. If $. \Delta \omega>0$, then $P_{D}$ will be negative i.e. exclusively rejecting the acceleration and if the $\Delta \omega<0, P_{D}$ will be positive and supporting $P_{e}$ in rejecting the deceleration. Subsequently, the rotor will follow the normal trajectory and synchronism is achieved without perpetual oscillations [3, 22]. It is worthwhile to note that the coefficient $D$ in physical SMs is not a constant value but depends on the condition of operation of the machine. Therefore, using a fixed value of $D$ in a reduced order model will not capture the performance of SM in the whole operating range [7].

\subsection{Speed-Droop Characteristics for Load Sharing}

Under steady state condition, the rotor speed of SG is proportional to the frequency of the armature current and subsequently to the frequency of the terminal voltage [23] as evident from the following equation;

$$
f_{e}=\left(\frac{n P}{120}\right)
$$

where; $f_{e}$ is the SG voltage frequency, $n$ is the rotor mechanical speed, $P$ is the number of poles.

Furthermore, considering the swing equation, it is evident that in an event of an imbalance between the input mechanical power to the generator and the electrical output power to the grid, the rotor speed will change. The speed-load dependence of the SGs connected in parallel can be represented by the following curve.

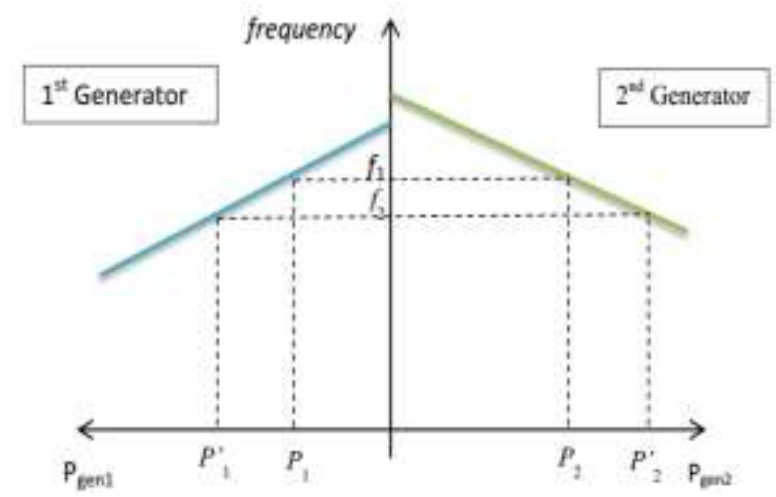

Fig. 3 Speed-droop characteristics of a synchronous generator

When two generator sets operate in parallel in an islanded mode, they share the same frequency $f_{1}$ as shown in the diagram. If the load in the system increases remarkably, the additional load will be shared according to the droop settings of the two generator sets and their frequency will change to $f_{2}$. Nonetheless, substantial drops in frequency below a particular threshold values can be dangerous to the system components. In this case, the adjustment of the governor reference is required and subsequently leads to a total generation increase of $P_{1}^{\prime}$ and $P_{2}^{\prime}$ due to governor response of the two generator sets respectively $[23,24]$.

\section{VIRTUAL SYNCHRONOUS GENERATOR CONCEPT}

The VSG principle is based on integrating the advantages of dynamic converter technology with those of the static and dynamic operating characteristics of electromechanical SMs [2]. The pictorial representation of VSG concept is as shown in Fig. 4. The three distinct components of VSG are PEC (which comprises of two power conversion stages, namely a DC to DC stage and a DC to AC stage), an energy storage device (battery, supercapacitor, flywheel, etc.) and the control scheme that controls the power exchange between energy storage and power system. This power exchange supports power system by preventing frequency fluctuations similar to SG rotational inertial $[8,25]$. The VSG is commonly placed in-between a DG (or DC source) and the grid [8]. The DC source that goes to the VSG algorithm performs the function of SG by providing inertia and damping supports to the grid system. 


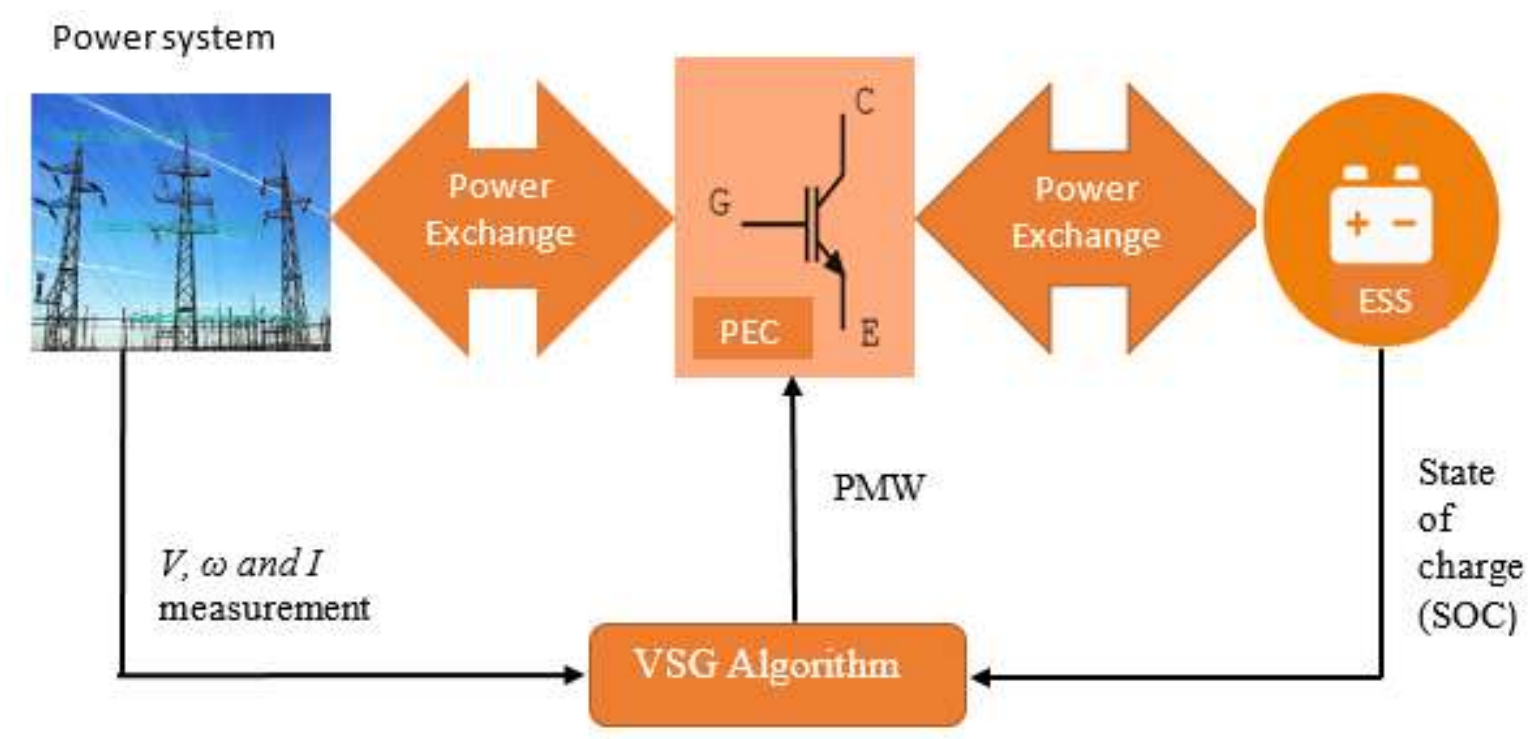

Fig. 4 Basic configuration and concept of the VSG [8, 25]

This is achieved by active power regulation of the inverter in inverse proportion of the rotor speed. The electrical features of the VSG are the same with that of conventional SG from the network viewpoint, apart from the high-frequency noise from the power transistors in the inverter. Due to the presence of an energy storage system (ESS), the VSG is able to absorb or inject (charge or discharge) power into the system. The nominal state of charge (SOC) of the ESS is suggested to be $50 \%$, and the lower and upper limits should be $20 \%$ and $80 \%$ respectively [7]. When the state of charge of ESS is within the limits, the VSG is working in its active operation, when there is excess energy in the system; the VSG is working on the virtual load operation [8].

The main idea of VSG is to mimic the important features of a traditional SG by using PEC control. Therefore, any VSG application involves approximately a direct mathematical model of a SG [7]. The choice of any SG model and its parameters are mainly based on the random choice of design as demonstrated by several solutions proposed in literature. Although, the mimicry of the inertial characteristics and damping features of electromechanical oscillations are the usual characteristics of every VSG implementation. Depending on the required extent of complexity and accuracy in replicating the SG dynamics, the transient and sub-transient dynamics of an SG model can be added or ignored [7]. Moreover, parameters' selection for VSG applications is not restricted by the physical design of any conventional SG model, consequently, the VSG parameters can be chosen to mimic a particular behaviour of SG model or can be defined in the course of control system development to obtain the required characteristics [7]. The power output of a VSG can be solely represented as follows:

$$
P_{V S G}=P_{o}+K_{\omega} \frac{d \Delta \omega}{d t}+K_{D} \Delta \omega
$$

Where; $P_{V S G}$ is the output power of VSG, $\Delta \omega=\omega-$ $\omega_{o}, \omega_{o}$ is the nominal grid frequency, $P_{o}$ represents the initial power to be transferred to the inverter, $K_{\omega} \frac{d \Delta \omega}{d t}$ represents the power regulation term of the VSG, depending on the initial rate of change of frequency $\left(\frac{d \Delta \omega}{d t}\right)$, if positive or negative, power will either be absorbed or injected into the system, $K_{\omega}$ denotes the inertia emulation characteristic of VSG. Since the rate of change of frequency gives an error signal, power exchange takes place during the transient event and stabilizes the frequency. This brings about the third term in the equation (3), $K_{D}$ mimics the damping effect of damper windings in an SG, and its value must be properly selected to commensurate with the fluctuations in system frequency [26].

Although, the system frequency and rotational speed dip can be minimized by increasing the virtual mass $\left(K_{\omega}\right)$, however, the synchronous units may likely increase the oscillation [26]. In an event of a disturbance, $K_{\omega}$ minimizes the maximum variation of the rotor speed; but the natural frequency and damping ratio may be reduced [27]. In effect, $K_{\omega}$ suppresses the system frequency dip and $K_{D}$ (virtual damper) counteracts the frequency oscillation of the 
grid. $K_{\omega}$ and $K_{D}$ are negative constant gains and should be fixed for maximum active power interchange [8]. In an event of maximum frequency excursion and rate of change of frequency, more power will either be injected or absorbed into/from the system depending on the frequency signal. In conventional SG, energy is absorbed by the damper winding resistance, which is subsequently dissipated as heat. However, in VSG the ESS is employed to absorb power fluctuation to balance the system. These characteristics symbolize the emulation of electromechanical SGs.

\section{REVIEW OF THE EXISTING VIRTUAL SYNCHRONOUS GENERATOR CONTROL MECHANISM}

Beck and Hesse were the first to propose virtual synchronous machine (VSM) based control technique in 2007 [2], which was named VISMA where they modelled the two windings of the stator in $\mathrm{d}-\mathrm{q}$ frames and the inertia without any current loops. Similarly, researchers [28-30] employ only swing equation in their SM model. Likewise, authors in [31, 32] presented models without current controllers, however, in later work [33], the current controllers were added and swing equation was derived with the magnitude of the virtual back EMF generated by some reactive power command. Ashabani and Mohamed [34] propose a modified swing equation incorporating DC bus voltage balance and droop control. The same technique was used in [35] with the addition of current controllers. In all the techniques, the virtual back EMF is employed simply to produce PMW signals, which correlates with the dynamic operation of a conventional SG.

In these schemes, the output current is uncontrolled (remains unbounded) and limited either by virtual inductors or by actual boost inductors. Nevertheless, these VSG control strategies are the easiest techniques, however, the probable overcurrent problem affects its deployment in case of large transients. Fig. 5 summarizes the control strategy, where a common grid-connected converter connects to the grid with an inductor, which could be a stepup transformer or output filter. From the Fig, the grid voltage $v_{a b c}$ and current $i_{a b c}$ are measured to compute $\mathrm{P}$ and $\mathrm{Q}$, and the same voltage may be employed by PLL to get the frequency of the grid $\left(f_{\text {grid }}\right)$. The output from either Q-control or V-control and the phase $\theta$ from the VSG model are fed to the PWM for the control of the converter, with this control scheme different implementation was employed by different authors.

Similar control strategy was proposed in [38], in which the traditional cascaded controller with inner current loops and outer voltage loops was employed; only the inertia emulation was implemented using swing equation. The scheme was enhanced in [39, 40] in which they control the output current rather than the virtual back EMF. structure as an enhanced model of synchroverter.

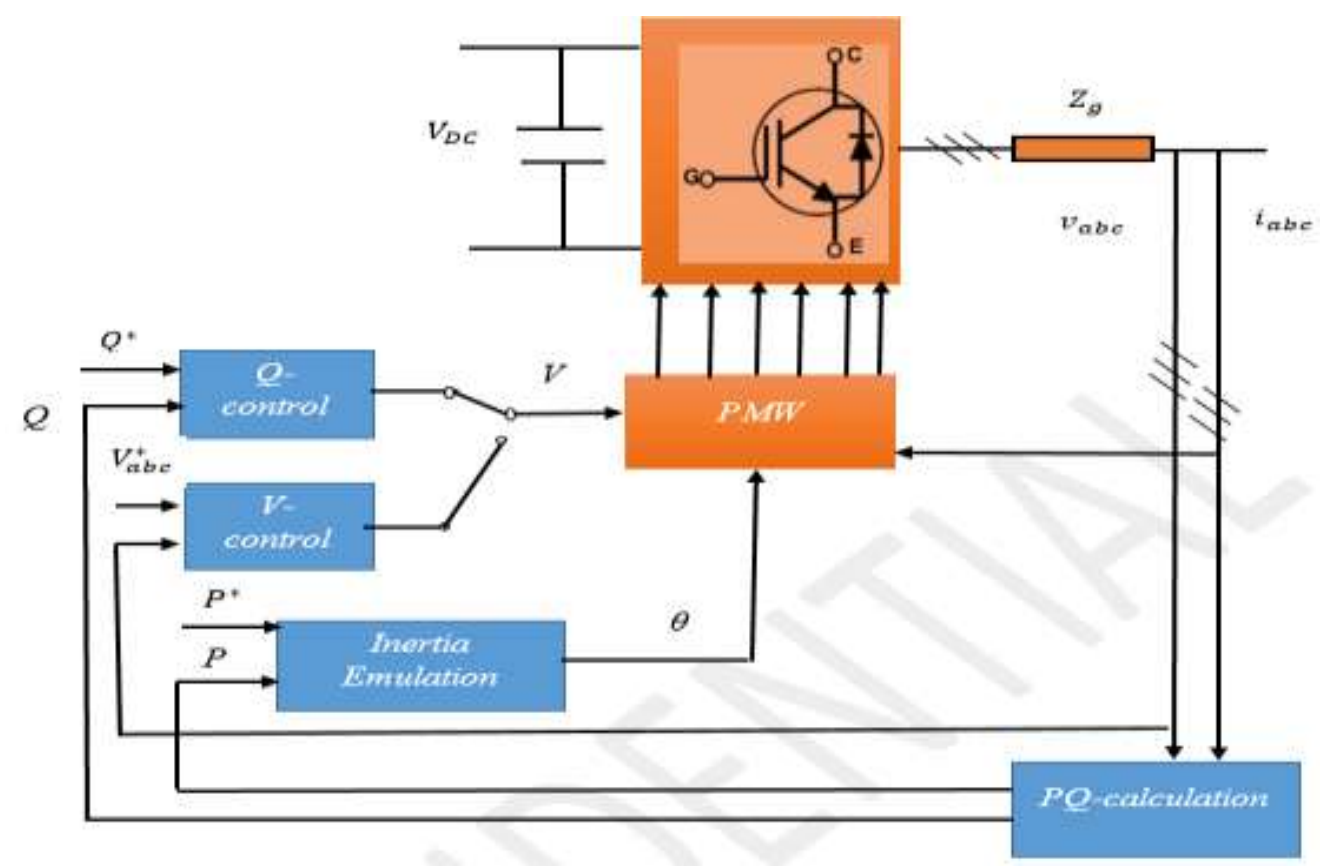

Fig. 5 VSG model without a current control loop [7, 9, 36, 37] 
The current control loop was incorporated to mitigate the problems. Authors in [41, 42] improve the current controller by incorporating virtual impedance in order to enhance the model performances such as elimination of harmonics and negative sequence compensation. Authors in $[9,43]$ improve the control scheme to realize autonomous coordination while $[44,45]$ and [46] also employed the same control Fig. 6 shows the general control structure for the VSG control strategies with an inner current loop. The major discrepancy from the previous type is that the output voltage from the VSG model passes through a current controller rather than PWM directly, where the voltage vector can be termed as virtual back EMF to differentiate it from actual output voltage vector. The current references from the control block can either be incorporated into the VSG model or as a separate block termed as virtual impedance. The virtual impedance has the functionalities to regulate current at a different frequency and different sequence to ease the transformation from islanded mode to grid-connected mode, and to presents more damping effect, etc. implementation of an advanced current control scheme can be employed to simplify the virtual impedance. The current controllers are simply derived from $\mathrm{d}-\mathrm{q}$ frame for simplicity of the control. Moreover, the phase information required by the park transformation is obtained from PLL in some literature for parameter optimization.

Some different cascaded schemes as shown in Fig 7 were presented in $[47,48]$. In those schemes, the current reference is not from the VSG model (inertia emulation block), and VSG model simply act as an alternative synchronization strategy replacing the PLL, making the scheme more homogenous to the traditional cascaded controller. The current reference is conventionally derived from the DC voltage regulator in the $d$ channel and $A C$ voltage regulator in q channel. In this case, more functionalities can be added through modifications. Therefore, the full control scheme becomes very easy; however, based on our knowledge, comparison with the previous schemes has not been investigated.

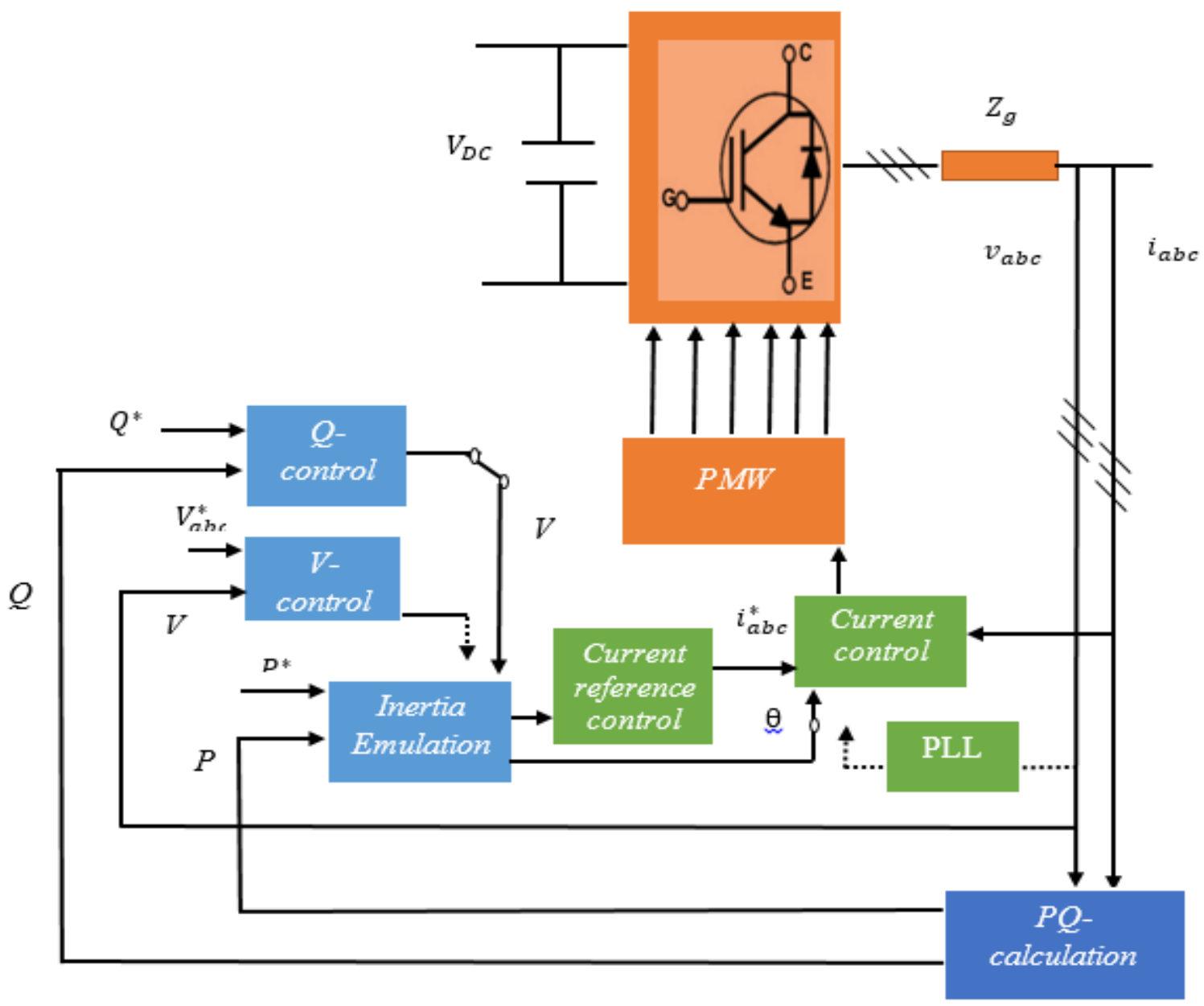

Fig. 6 VSG model incorporating current control loop $[7,9,36,37]$ 
Generally, emulation of inertia characteristic using swing equation is enough to supply system frequency information. Hence, PLL in the traditional $d-q$ channel control can be substituted or used as an alternative back up during start-up or contingencies events. Authors in [50] proposed an interesting model in which PLL is employed to obtain the system frequency that is different from the VSG frequency in order to perform automatic tuning of the controller parameters.

Although each type has different variations, several researchers tend to focus more on cascaded controller having only inertia emulation. This is because virtual inertia gives the converters the potential to expend their energy storage to increase the entire system inertia for frequency stability [51] while maintaining synchronism with other rotating units, in addition to accessibility to droop control to operate without centralized control. The overall control schemes can be grouped into two types: direct back EMF and current loop controller; classification by SM models are also of two kinds: a simple model with only inertia emulation and a complete model with both inertia and dynamics in flux.

There are few papers, which focus on modelling and design, while others only presented control schemes theoretically without giving reasons to back their proposed schemes. In [9, 43, 52], the full state space model of VSG controlled converter was derived to realize the pole-zero map to observe the influences and the sensitivity from each state to each mode was discussed. A similar investigation was discussed in [47, 53, 54]. This technique is capable of accomplishing control over the entire system provided the system is controllable which is usually characterized by the power system structure. Nevertheless, the disadvantage of the method is large computations requirement and some parameters or states may not be feasible. A reduced model was proposed in [55] to present some fundamental stability limit analysis.

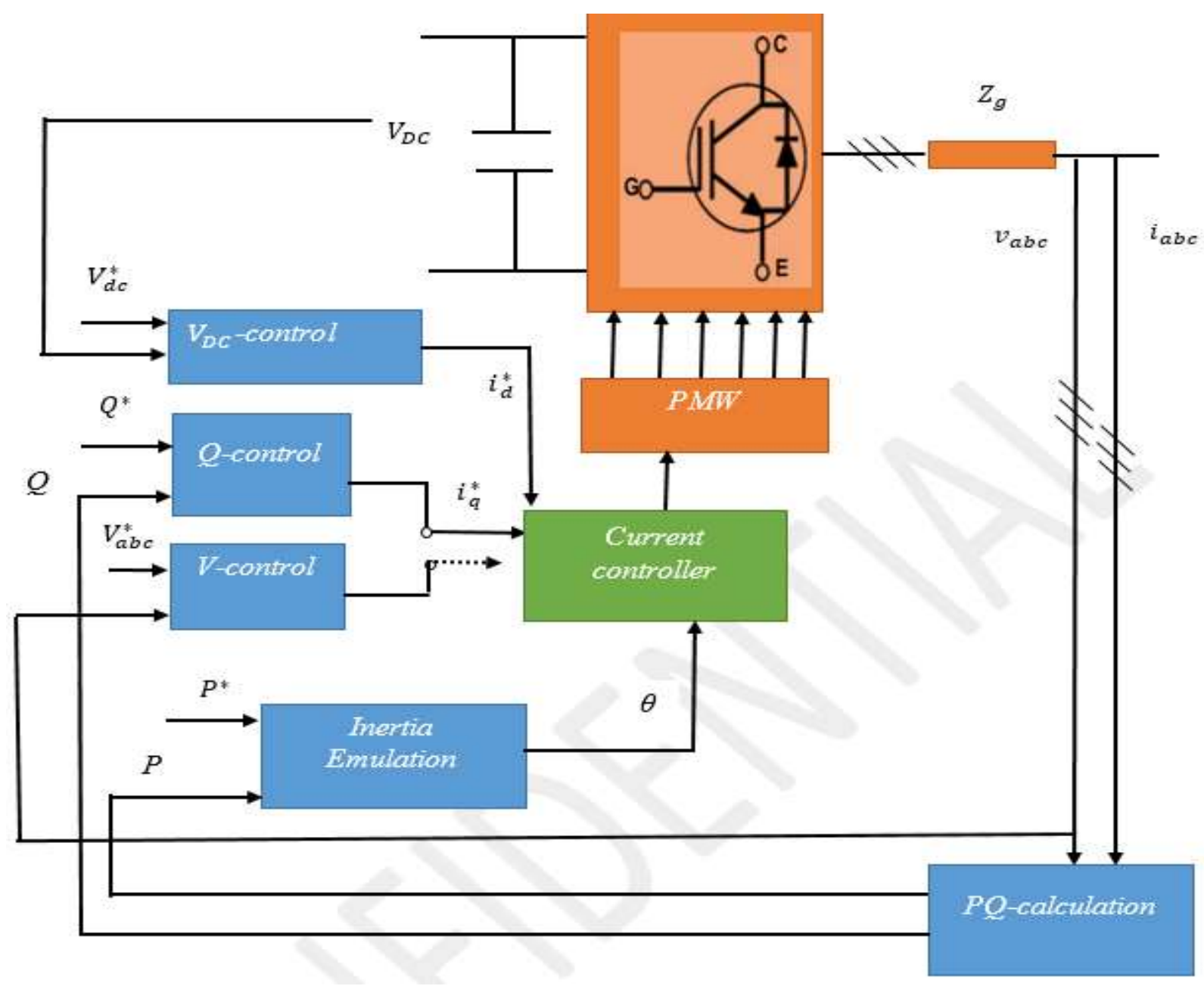

Fig. 7 VSG model with modified current control loop $[7,9,37,49]$ 
Different design process focused on transfer function and Bode plots was presented in $[56,57]$ to reduce the computation problem in the previous model. In $[50,58]$, some simplification was employed by tuning control parameters online, in order to realize better performance and efficient damping effect. Full state space model is rarely used due to the nonlinearity of the model. Energy functions and Lyapunov method are considered as an efficient technique as in [28, $30,35,59]$, however, it is not feasible for complex systems.

If the entire dynamic characteristics of SG is to be reproduced by VSG, the SG model incorporating a full order features of SG has to be modelled [7, 22, 24] and this would results in $7^{\text {th }}$ order model. However, if the objective of the VSG implementation is to mimic the inertia and damping characteristics of the SG, using full order model of SG will add nonessential complexity in the model. The two properties (inertia and damping characteristics) can be captured by the general swing equation [7].

\section{APPLICATIONS}

The VSG control strategy can be used for all types of generation units, e.g. PV farms [41], electric vehicles $[45,53,54,60,61]$, STATCOMs $[25,32,34,56,57]$, and conventional DGs $[9,31,33,48]$, because of its inherent features which enables it to participate in frequency stability support.

It can also be employed to perform some conventional power system functions, such as oscillation damping $[28,39,50,62]$ and low voltage ride through [42] by adjusting the control loops, usually incorporating feedback and increase the order of compensators. Although, these have not been investigated much because the VSG control schemes are still under development.

The highlighted control schemes are based on simulations and experimental studies, VSG is still under developmental stage. Most of the existing literature on VSG is about proposals of various control schemes, modelling, design and application. However, there is still a great deal of investigations that need to be done as highlighted in the next section because the concept is still new and to the best of our knowledge, no practical implementation is under operation yet.

\section{Challenges that aRe needed to Be ADDRESSED}

- It is very important to present a quantitative design process with respect to known system parameters and the corresponding sensitivities in order to have a robust controller, which can withstand various system operating points.

- Efficient and robust control scheme can still be achieved through improvement of the existing models by further study of the mathematical derivation of the equivalency between the VSG concept and SG where only the preferable parts are utilized.

- More research is required regarding the control of ESS in the VSG control scheme, a robust technique to supervise the state of charge of the ESS system in response to system instability.

- More real-time experiments need to be conducted to see the influence and performance of VSG controller.

- An important characteristic of VSG is its fastness in counteracting power system deviations to support frequency stability. In an event of power imbalance, VSG injects or absorbs power into/from the system to mitigate the frequency excursion and this takes place within few seconds, the traditional SG needs to react to a huge change in power by adjusting its generation to balance the system. However, the fastness of the VSG in counteracting the frequency excursion may affect the response of the SG. Therefore, a robust coordination between VSG and SG is crucial for effective power control.

- The system reliability should also be emphasized, the generation reliability of the grid integrated DGs should be constantly assessed and the reliability assessment techniques for this type of alloyed systems should be standardized and explicit enough in order to have a robust and efficient system.

\section{CONCLUSION}

The continuous growth in the integration of DGs in the power system network, for the reason of stability and sustainability, has contributed to the imbalance in traditional power system structure. The DGs systems have little or no inertia and damping property as found in the conventional SGs, thereby causing a total decrease in the entire system inertia. This paper has presented an overview of the crucial issues regarding the influence of the DGs in power system network, the VSG control schemes and their applications, the challenges that are needed to be addressed and the necessary improvement in the 
existing control scheme as stipulated in section 6 of this paper.

\section{REFERENCES}

[1] P. UNION, "DIRECTIVE 2009/28/EC OF THE EUROPEAN PARLIAMENT AND OF THE COUNCIL of 23âApril 2009 on the promotion of the use of energy from renewable sources and amending and subsequently repealing Directives 2001/77/EC andâ2003/30/EC," ed: EC, 2009.

[2] H.-P. Beck and R. Hesse, "Virtual synchronous machine," in 2007 9th International Conference on Electrical Power Quality and Utilisation, pp. 1-6: IEEE, 2007.

[3] A. Perera, "Virtual synchronous machine-based power control in active rectifiers for micro grids," 2012.

[4] G. Chicco and P. Mancarella, "Distributed multigeneration: a comprehensive view," Renewable and Sustainable Energy Reviews, vol. 13, no. 3, pp. 535-551, 2009.

[5] A. Llaria, O. Curea, J. Jiménez, and $H$. Camblong, "Survey on microgrids: unplanned islanding and related inverter control techniques," Renewable energy, vol. 36, no. 8, pp. 2052-2061, 2011.

[6] J. Byrne et al., GLOBAL TRENDS IN RENEWABLE ENERGY INVESTMENT 2016. http://www.fs-unep-centre.org: Frankfurt School of Finance \& Management $\mathrm{gGmbH}$ 2016, 2016.

[7] S. D'Arco and J. A. Suul, "Virtual synchronous machines-Classification of implementations and analysis of equivalence to droop controllers for microgrids," in PowerTech (POWERTECH), 2013 IEEE Grenoble, pp. 1-7: IEEE, 2013.

[8] H. Bevrani, T. Ise, and Y. Miura, "Virtual synchronous generators: A survey and new perspectives," International Journal of Electrical Power \& Energy Systems, vol. 54, pp. 244-254, 2014.

[9] S. D'Arco, J. A. Suul, and O. B. Fosso, "A Virtual Synchronous Machine implementation for distributed control of power converters in SmartGrids," Electric Power Systems Research, vol. 122, pp. 180-197, 2015.

[10] R. Aouini, K. B. Kilani, B. Marinescu, and M. Elleuch, "Virtual synchronous generators dynamic performances," in Electrical Sciences and Technologies in Maghreb (CISTEM), 2014 International Conference on, pp. 1-6: IEEE, 2014.

[11] S. Barcellona, Y. Huo, R. Niu, L. Piegari, and E. Ragaini, "Control strategy of virtual synchronous generator based on virtual impedance and band-pass damping," in Power Electronics, Electrical Drives, Automation and
Motion (SPEEDAM), 2016 International Symposium on, pp. 1354-1362: IEEE, 2016.

[12] Y. Chen, R. Hesse, D. Turschner, and H.-P. Beck, "Comparison of methods for implementing virtual synchronous machine on inverters," in International Conference on Renewable Energies and Power QualityICREPQ'12, 2012.

[13] J. Slootweg and W. Kling, "Impacts of distributed generation on power system transient stability," in Power Engineering Society Summer Meeting, 2002 IEEE, vol. 2, pp. 862-867: IEEE, 2002.

[14] J. M. Guerrero, J. Matas, L. G. De Vicuña, N. Berbel, and J. Sosa, "Wireless-control strategy for parallel operation of distributed generation inverters," in Industrial Electronics, 2005. ISIE 2005. Proceedings of the IEEE International Symposium on, vol. 2, pp. 845-850: IEEE, 2005.

[15] N. Pogaku, M. Prodanovic, and T. C. Green, "Modeling, analysis and testing of autonomous operation of an inverter-based microgrid," IEEE Transactions on power electronics, vol. 22, no. 2, pp. 613-625, 2007.

[16] W. Yao, M. Chen, J. Matas, J. M. Guerrero, and Z.-M. Qian, "Design and analysis of the droop control method for parallel inverters considering the impact of the complex impedance on the power sharing," IEEE Transactions on Industrial Electronics, vol. 58, no. 2, pp. 576-588, 2011.

[17] J. C. Vasquez, J. M. Guerrero, A. Luna, P. Rodríguez, and R. Teodorescu, "Adaptive droop control applied to voltage-source inverters operating in grid-connected and islanded modes," IEEE Transactions on Industrial Electronics, vol. 56, no. 10, pp. 4088-4096, 2009.

[18] X. Haizhen, Z. Xing, L. Fang, M. Fubin, S. Rongliang, and N. Hua, "An improved virtual synchronous generator algorithm for system stability enhancement," in Future Energy Electronics Conference (IFEEC), 2015 IEEE 2nd International, pp. 1-6: IEEE, 2015.

[19] T. V. Van et al., "Virtual synchronous generator: An element of future grids," in Innovative Smart Grid Technologies Conference Europe (ISGT Europe), 2010 IEEE PES, pp. 17: IEEE, 2010.

[20] R. Hesse, D. Turschner, and H.-P. Beck, "Micro grid stabilization using the Virtual Synchronous Machine (VISMA)," in Proceedings of the International Conference on Renewable Energies and Power Quality (ICREPQ'09), Valencia, Spain, pp. 15-17, 2009.

[21] H. Bevrani and T. Ise, Microgrid dynamics and control. John Wiley \& Sons, 2017. 
[22] J. Machowski, J. Bialek, and J. Bumby, Power system dynamics: stability and control. John Wiley \& Sons, 2011.

[23] A. E. Fitzgerald, C. Kingsley, S. D. Umans, and B. James, Electric machinery. McGraw-Hill New York, 2003.

[24] P. Kundur, N. J. Balu, and M. G. Lauby, Power system stability and control. McGraw-hill New York, 1994

[25] V. Karapanos, P. Kotsampopoulos, and N. Hatziargyriou, "Performance of the linear and binary algorithm of virtual synchronous generators for the emulation of rotational inertia," Electric Power Systems Research, vol. 123, pp. 119-127, 2015.

[26] V. Karapanos, S. de Haan, and K. Zwetsloot, "Testing a virtual synchronous generator in a real time simulated power system," in Proc. Int. Conf. on Power Systems Transients (IPST), 2011.

[27] M. Torres and L. A. Lopes, "Virtual synchronous generator control in autonomous wind-diesel power systems," in Electrical Power \& Energy Conference (EPEC), 2009 IEEE, pp. 1-6: IEEE, 2009.

[28] J. Alipoor, Y. Miura, and T. Ise, "Distributed generation grid integration using virtual synchronous generator with adoptive virtual inertia," in Energy Conversion Congress and Exposition (ECCE), 2013 IEEE, pp. 4546-4552: IEEE, 2013.

[29] C. Han et al., "STATCOM impact study on the integration of a large wind farm into a weak loop power system," IEEE Transactions on energy conversion, vol. 23, no. 1, pp. 226-233, 2008.

[30] J. Alipoor, Y. Miura, and T. Ise, "Power system stabilization using virtual synchronous generator with alternating moment of inertia," IEEE Journal of Emerging and Selected Topics in Power Electronics, vol. 3, no. 2, pp. 451-458, 2015.

[31] Q.-C. Zhong and G. Weiss, "Synchronverters: Inverters that mimic synchronous generators," IEEE Transactions on Industrial Electronics, vol. 58, no. 4, pp. 1259-1267, 2011.

[32] P.-L. Nguyen, Q.-C. Zhong, F. Blaabjerg, and J. M. Guerrero, "Synchronverter-based operation of STATCOM to mimic synchronous condensers," in Industrial Electronics and Applications (ICIEA), 2012 7th IEEE Conference on, pp. 942-947: IEEE, 2012.

[33] Q.-C. Zhong, P.-L. Nguyen, Z. Ma, and W. Sheng, "Self-synchronized synchronverters: Inverters without a dedicated synchronization unit," IEEE Transactions on Power Electronics, vol. 29, no. 2, pp. 617-630, 2014.
[34] M. Ashabani and Y. A.-R. I. Mohamed, "Novel comprehensive control framework for incorporating VSCs to smart power grids using bidirectional synchronous-VSC," IEEE Transactions on Power Systems, vol. 29, no. 2, pp. 943-957, 2014.

[35] M. Ashabani and Y. A.-R. I. Mohamed, "Integrating VSCs to weak grids by nonlinear power damping controller with selfsynchronization capability," IEEE Transactions on Power Systems, vol. 29, no. 2, pp. 805-814, 2014.

[36] X. Dong, H. Lin, R. Tan, R. K. Iyer, and Z. Kalbarczyk, "Software-defined networking for smart grid resilience: Opportunities and challenges," in Proceedings of the 1st ACM Workshop on Cyber-Physical System Security, pp. 61-68: ACM, 2015.

[37] J. Liu, Y. Miura, and T. Ise, "Comparison of dynamic characteristics between virtual synchronous generator and droop control in inverter-based distributed generators," IEEE Trans. Power Electron, vol. 31, no. 5, pp. 36003611, 2016.

[38] L. Zhang, L. Harnefors, and H.-P. Nee, "Powersynchronization control of grid-connected voltage-source converters," IEEE Transactions on Power systems, vol. 25, no. 2, pp. 809-820, 2010.

[39] Y. Chen, R. Hesse, D. Turschner, and H.-P. Beck, "Improving the grid power quality using virtual synchronous machines," in Power engineering, energy and electrical drives (POWERENG), 2011 international conference on, pp. 1-6: IEEE, 2011.

[40] Y. Chen, R. Hesse, D. Turschner, and H.-P. Beck, "Investigation of the virtual synchronous machine in the island mode," in Innovative Smart Grid Technologies (ISGT Europe), 2012 3rd IEEE PES International Conference and Exhibition on, pp. 1-6: IEEE, 2012.

[41] P. Rodriguez, I. Candela, and A. Luna, "Control of PV generation systems using the synchronous power controller," in Energy Conversion Congress and Exposition (ECCE), 2013 IEEE, pp. 993-998: IEEE, 2013.

[42] D. Remon, A. M. Cantarellas, E. Rakhshani, I. Candela, and P. Rodriguez, "An active power self-synchronizing controller for grid-connected converters emulating inertia," in Renewable Energy Research and Application (ICRERA), 2014 International Conference on, pp. 424429: IEEE, 2014.

[43] S. D'Arco, J. A. Suul, and O. B. Fosso, "Control system tuning and stability analysis of virtual synchronous machines," in Energy Conversion Congress and Exposition (ECCE), 2013 IEEE, pp. 2664-2671: IEEE, 2013. 
[44] J. Zhu, J. M. Guerrero, W. Hung, C. D. Booth, and G. P. Adam, "Generic inertia emulation controller for multi-terminal voltage-sourceconverter high voltage direct current systems, IET Renewable Power Generation, vol. 8, no. 7, pp. 740-748, 2014.

[45] J. Zhu, C. D. Booth, G. P. Adam, A. J. Roscoe, and C. G. Bright, "Inertia emulation control strategy for VSC-HVDC transmission systems," IEEE Trans. Power Syst, vol. 28, no. 2, pp. 1277-1287, 2013.

[46] S. Dong, Y. Chi, and Y. Li, "Active voltage feedback control for hybrid multiterminal HVDC system adopting improved synchronverters," IEEE Transactions on Power Delivery, vol. 31, no. 2, pp. 445-455, 2016.

[47] Y. Du, J. M. Guerrero, L. Chang, J. Su, and M. Mao, "Modeling, analysis, and design of a frequency-droop-based virtual synchronous generator for microgrid applications," in ECCE Asia Downunder (ECCE Asia), 2013 IEEE, pp. 643-649: IEEE, 2013.

[48] M. Guan, W. Pan, J. Zhang, Q. Hao, J. Cheng, and $X$. Zheng, "Synchronous generator emulation control strategy for voltage source converter (VSC) stations," IEEE Trans. Power Syst, vol. 30, no. 6, pp. 3093-3101, 2015.

[49] C. Li, "Design, Analysis and Experimental Evaluation of a Virtual Synchronous Machine Based Control Scheme for STATCOM Applications," Virginia Tech, 2015.

[50] L. A. Lopes, "Self-tuning virtual synchronous machine: A control strategy for energy storage systems to support dynamic frequency control," IEEE Transactions on Energy Conversion, vol. 29, no. 4, pp. 833-840, 2014.

[51] S. D'Arco and J. A. Suul, "Equivalence of virtual synchronous machines and frequency-droops for converter-based microgrids," IEEE Transactions on Smart Grid, vol. 5, no. 1, pp. 394-395, 2014.

[52] S. D'Arco, J. A. Suul, and O. B. Fosso, "Automatic tuning of cascaded controllers for power converters using eigenvalue parametric sensitivities, " IEEE Transactions on Industry Applications, vol. 51, no. 2, pp. 1743-1753, 2015.

[53] L. Zhang, L. Harnefors, and H.-P. Nee, "Modeling and control of VSC-HVDC links connected to island systems," IEEE Transactions on Power Systems, vol. 26, no. 2, pp. 783-793, 2011.
[54] L. Zhang, L. Harnefors, and H.-P. Nee, "Interconnection of two very weak AC systems by VSC-HVDC links using powersynchronization control," IEEE transactions on power systems, vol. 26, no. 1, pp. 344-355, 2011.

[55] L. Zhang, H.-P. Nee, and L. Harnefors, "Analysis of stability limitations of a VSC-HVDC link using power-synchronization control," IEEE Transactions on Power Systems, vol. 26, no. 3, pp. 1326-1337, 2011.

[56] C. Li, R. Burgos, I. Cvetkovic, D. Boroyevich, L. Mili, and P. Rodriguez, "Evaluation and control design of virtual-synchronous-machine-based STATCOM for grids with high penetration of renewable energy," in Energy Conversion Congress and Exposition (ECCE), 2014 IEEE, pp. 5652-5658: IEEE, 2014.

[57] C. Li, R. Burgos, I. Cvetkovic, D. Boroyevich, L. Mili, and P. Rodriguez, "Analysis and design of virtual synchronous machine based STATCOM controller," in Proceedings of the IEEE 15th Workshop on Control and Modeling for Power Electronics (COMPEL), Santander, Spain, pp. 22-25, 2014.

[58] S. Kazemlou and S. Mehraeen, "Novel decentralized control of power systems with penetration of renewable energy sources in small-scale power systems," IEEE Transactions on Energy Conversion, vol. 29, no. 4, pp. 851861, 2014.

[59] J. Alipoor, Y. Miura, and T. Ise, "Voltage sag ride-through performance of virtual synchronous generator," IEEJ Journal of Industry Applications, vol. 4, no. 5, pp. 654666, 2015.

[60] P. Mitra, L. Zhang, and L. Harnefors, "Offshore wind integration to a weak grid by VSC-HVDC links using power-synchronization control: $A$ case study," IEEE Transactions on Power Delivery, vol. 29, no. 1, pp. 453-461, 2014.

[61] R. Aouini, B. Marinescu, K. B. Kilani, and M. Elleuch, "Synchronverter-based emulation and control of HVDC transmission," IEEE Transactions on Power Systems, vol. 31, no. 1, pp. 278-286, 2016.

[62] T. Shintai, Y. Miura, and T. Ise, "Oscillation damping of a distributed generator using a virtual synchronous generator," IEEE transactions on power delivery, vol. 29, no. 2, pp. 668-676, 2014. 